\title{
Comparison of transmission and distribution systems in the Czech Republic and Spain
}

\author{
F. Rajský ${ }^{1}$, M. P. Donsión ${ }^{2}$ \\ ${ }^{1}$ Department of Electric power engineering and Ecology \\ Faculty of electrical engineering Plzeň., The University of West Bohemia in Pilsen \\ Univerzitni 8; 30614 Pilsen; Czech Republic \\ phone: +420 776 8605232, fax:+420 37 7634301, e-mail: rajsky@kee.zcu.cz, \\ ${ }^{2}$ Electrical Engineering Department, Vigo University, Spain \\ Department of Electrical Engineering, University of Vigo, Campus of Lagoas Marcosende, 36310 Vigo (Spain), \\ IEEE, EA4EPQ and AEDIE member, donsion@vigo.es
}

\section{Introduction}

Electric power transmission, a process in the delivery of electricity to consumers, is the bulk transfer of electrical power. Typically, power transmission occurs between the power plant and a substation near a populated area. Electricity is then distributed from the substation to the consumers. Electric power transmission allows distant energy sources to be connected to consumers in population centers, and may allow exploitation of lowgrade fuel resources that would otherwise be too costly to transport to generating facilities.

Due to the large amount of power involved, transmission normally takes place at high voltage $(1150 \mathrm{kV}, 750 \mathrm{kV}$, $420 \mathrm{kV}, 220 \mathrm{kV}$ and $110 \mathrm{kV}$ ). Electricity is usually transmitted over long distances through overhead power transmission lines. Underground power transmission is used only in densely populated areas due to its high cost of installation and maintenance, and because the high reactive power produces large charging currents and difficulties in voltage management.

A power transmission system is sometimes referred to colloquially as a "grid"; however, for reasons of economy, the network is not a mathematical grid. Redundant paths and lines are provided so that power can be routed from any power plant to any load center through a variety of routes, based on the economics of the transmission path and the cost of power. Much analysis is performed by transmission companies to determine the maximum reliable capacity of each line, which, due to system stability considerations, may be less than the physical or thermal limit of the line. Deregulation of electricity companies in many countries has led to renewed interest in reliable, economic designs of transmission networks.

This paper will discuss Czech and Spanish electrical energy systems. The transmission networks of both countries are explained in the first two chapter. The third and fourth sections describe basic information about connections and electrical parameters in networks. The fifth and sixth section describes distribution network in both countries. Main problems with connection transmission networks to UCTE are addressed in the seventh section. The final section compares the transmission grid.

\section{Czech transmission network}

The CEPS s.o. (Czech Transmission company state organization) transmission system is part of the Czech power supply system, which links major entities operating within the power supply system. The majority of cross-border exchanges are carried out across this system. The CEPS transmission system comprises 38 substations of $420 \mathrm{kV}$ and $245 \mathrm{kV}$ located at 30 transformer stations, along with $2900 \mathrm{~km}$ of $400 \mathrm{kV}$ lines and $1440 \mathrm{~km}$ of $220 \mathrm{kV}$ lines. Two $123 \mathrm{kV}$ substations and 105 route kilometers of $110 \mathrm{kV}$ lines are also included in the transmission system.

The CEPS is responsible for electricity transfer, transmission system operation, maintenance and development, and real-time dispatch in the Czech power supply system. As a system service it further develops and tests a Defense Plan (to prevent failure spreading) and a Restoration Plan (to restore the power supply after major system failures). It provides technical management of system services such as power-frequency control and voltage and reactive power control, and is responsible for availability and efficient use of power reserves.

In the CEPS transmission system, 2628 route kilometers out of a total of 5454 route kilometers of high voltage lines $(110 \mathrm{kV}$ to $400 \mathrm{kV})$ are equipped with optical fibers. Total transformation capacity amounts to 17190 MVA in the 30 transformers that comprise the transmission system, and total compensation capacity is 1 436 MVA. See Table 1 for information on transmission system facilities and Figure 1 for a map of the transmission network.

By virtue of its design, the Czech Republic's $400 \mathrm{kV}$ and $220 \mathrm{kV}$ networks fully comply with the N-1 criterion. Stricter requirements apply to the connection of nuclear power stations. The full output of a nuclear power station must be safely supplied to the network even in the case of a simultaneous failure of two feeders from the power station's substation.

Investment projects currently under preparation are aimed at covering a sharp increase in demand in certain regions or improving the reliability and quality of supply. The projects also respond to changes in transit flows and requests for the connection of new centers of consumption or generation to the system. 
TABLE I. Technical information CEPS

\begin{tabular}{|l|l|r|}
\hline CEPS s.o. & Unit & Year 2006 \\
\hline Maximum download & MW & 18626 \\
\hline Longitude on VHVL & $\mathrm{km}$ & 12500 \\
\hline Transformers station & Piece & 170 \\
\hline
\end{tabular}

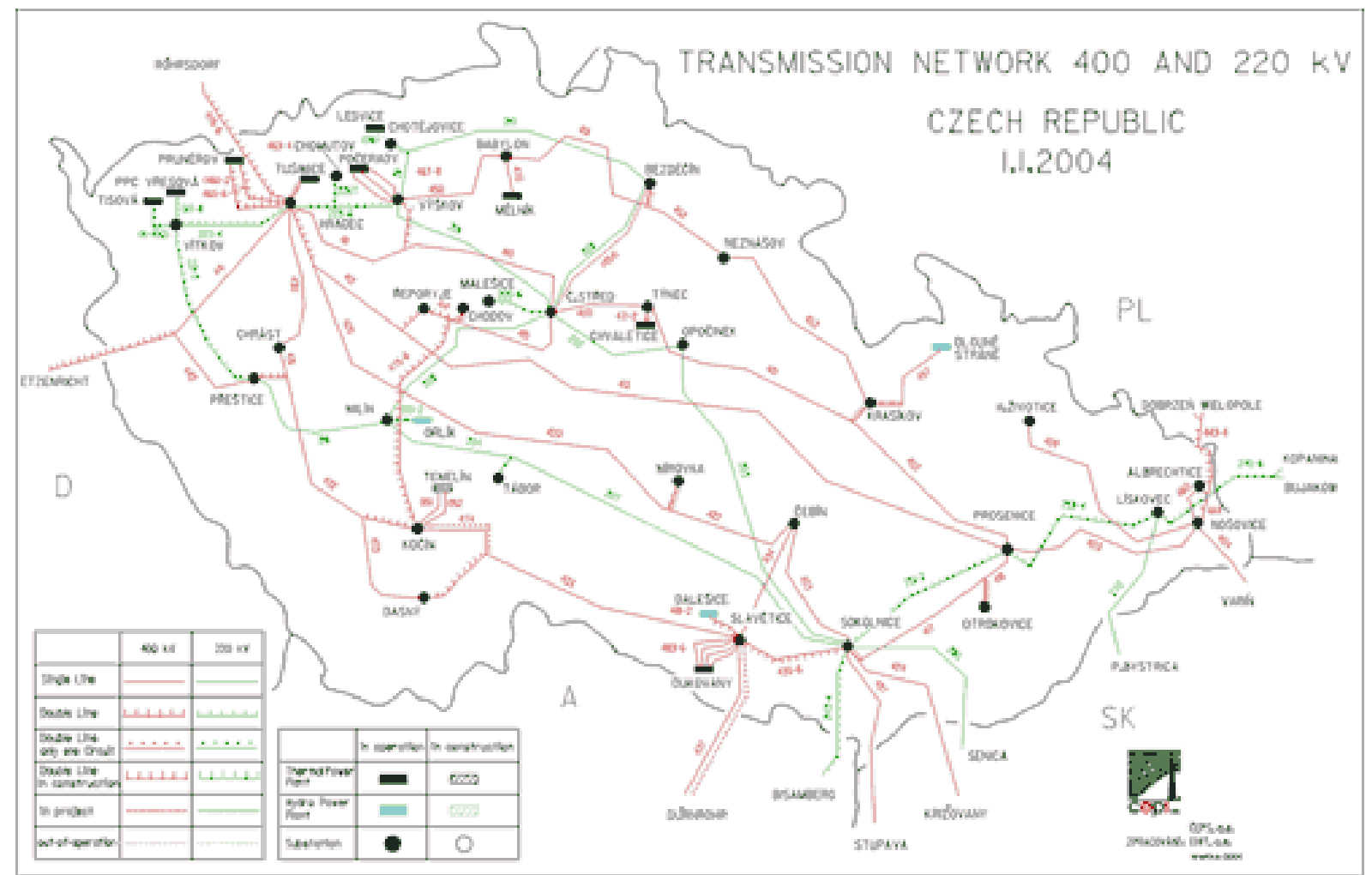

Fig. 1. Map of transmission network

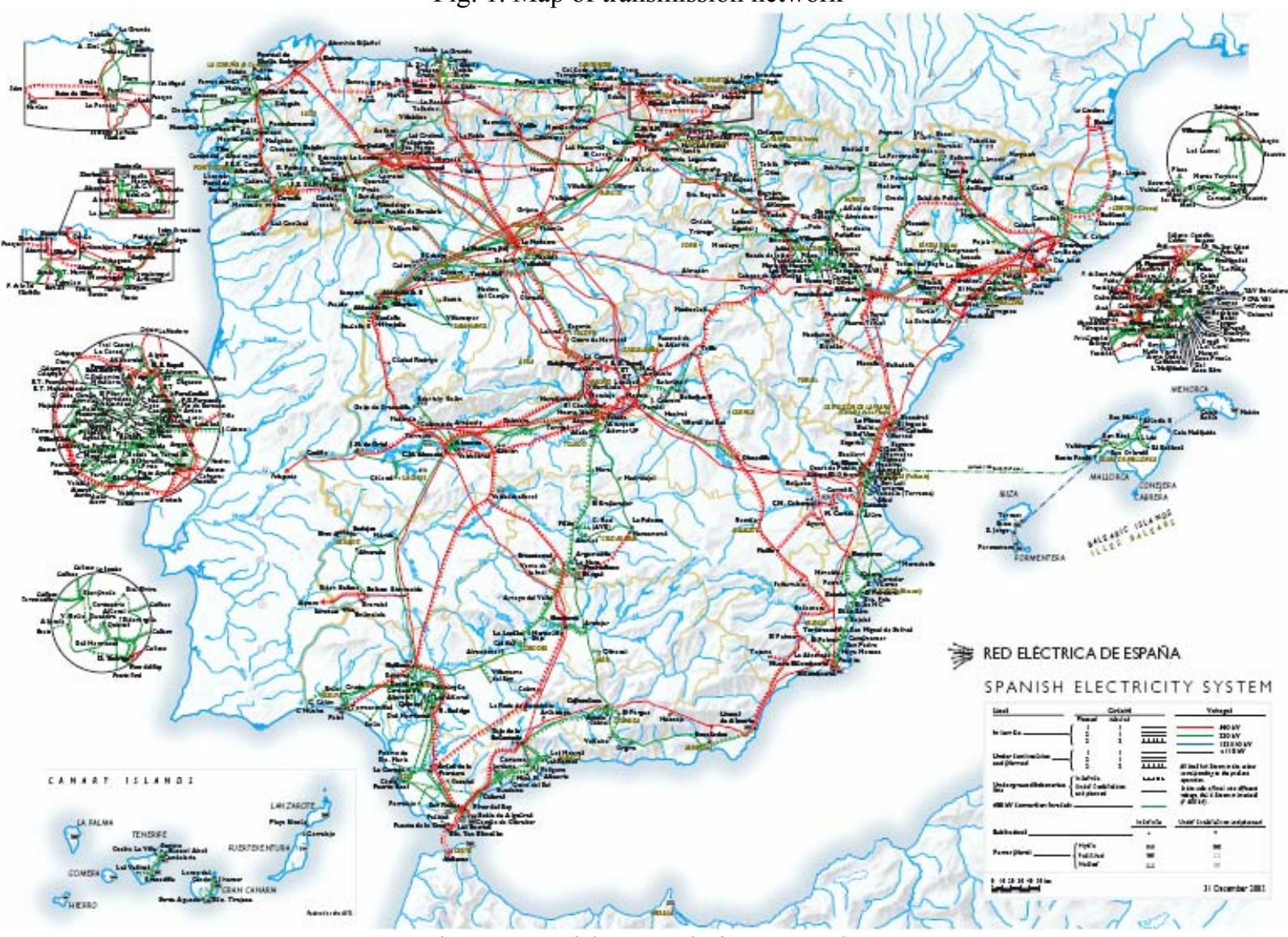

Fig. 2. Spanish transmission network 


\section{Spanish transmission network}

The Red Electrical company specializes in the transmission of electric power and is responsible for the operation of the power system as well as the management of the transmission grid (Fig. 2.).

Electrical energy cannot be stored. For this reason, production must equal consumption at all times, precisely and instantaneously. In order to transfer electric power from the areas of production to the areas of consumption it is necessary to have a constantly accessible connecting element: this is transmission network.

The basic installations of Red Electrical comprise the power control systems which direct and supervise the operation of the transmission system. This system consists of more than $33000 \mathrm{~km}$ of very high voltage transmission lines and 2905 substation circuit bays with more than 55400 MVA of transformer capacity.

As the company responsible for management of the transmission grid, Red Electrical must ensure the development and expansion of the high tension grid using uniform and coherent criteria, carry out maintenance to provide the required reliability and availability, and guarantee access by third parties to the transmission grid. In 1997, the Electricity Sector confirmed that Red Electrical plays a key role in the electricity system. This act created a wholesale electricity market which required a well-managed transmission network and an operation system that would coordinate generation and transmission as a whole, allowing the transfer of energy between producers and distributors and guaranteeing that demand would be met at all times.

As system operator, Red Electrical guarantees a balance between energy production and consumption, ensuring quality supply in all places and at all times, and provides the market system with the safety and liquidity it needs. Its specialization guarantees its independence and the use of non-discriminatory criteria regarding access to the electricity system by agents.

TABLE II. Technical information Red Electrical

\begin{tabular}{|l|l|r|}
\hline Red Eletrical Inc. & Unit & Year 2006 \\
\hline Maximum download & MW & 55400 \\
\hline Longitude on VHVL & $\mathrm{km}$ & 33000 \\
\hline Transformers station & Piece & 2905 \\
\hline
\end{tabular}

\section{Basic information about transmission network}

A good electrical network design calls for the knowledge of the currents, which flow in the lines either in an operating or under a design state. The network progresses depend of these currents that mean corresponding with power outputs. It is analysis in the case of the operating network, current calculation, voltage drop, power losses, frequency analysis, flickers, over voltage, time behavior of the short circuit ...

The Transmission network is an Effectively Grounded System on $400 \mathrm{kV}$ and $220 \mathrm{kV}$. This network is connected by a circuit way. A Super Grid, or VHVN (very high voltage network), is connected with other super grids in surrounding states. In the Europe is the correct connection, in UCTE (more information on seveth section) but with other states the connection is during AC- DC converter.

The Effectively Grounded System consists of three phases and one grounded conductor. During Phase One, short circuit grows up the current (ten KA), voltage flows to zero $(\mathrm{V})$ and on the rest phases is nominal voltage, but current flows to zero.

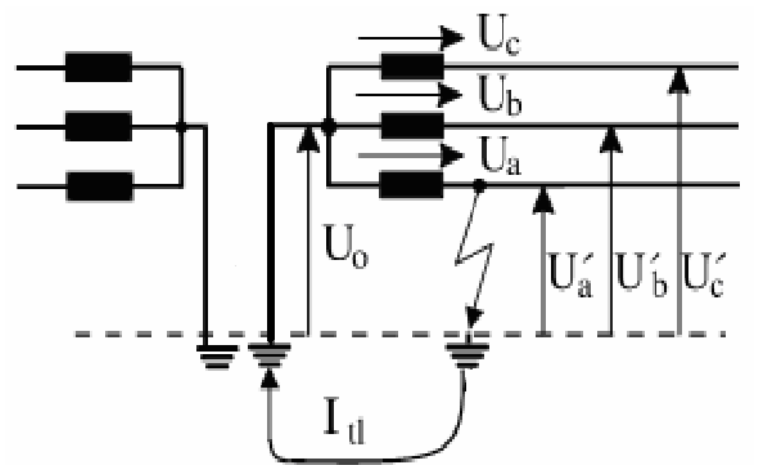

Fig. 3. Effectively Grounded Systems

The one phase short circuit is most important values for dimension a conductors.

$$
\begin{aligned}
I_{K}{ }^{\prime \prime} & =\frac{3 \cdot c \cdot U_{N}}{\sqrt{3} \cdot Z} \quad[A] \quad Z=Z_{1}+Z_{2}+Z_{0} \\
c & =1,1 \text { is_a_network_coeficient }
\end{aligned}
$$

The circuit way means transmission network topology. A transmission network graph is the geometric formation created by replacing all the network elements with directed node connections. A loop is a sequence of the defined number of uncrossing branches, which are connected to the nodes in such a sequence, that a path can be traced back to the initial point of the first branch. Typically transmission network are be run by ring graphic system is shown on fig 4 and fig 5 .

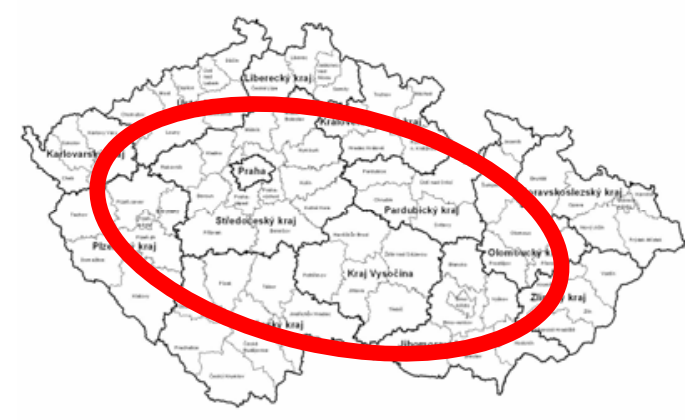

Fig. 4. Basic circuit topology

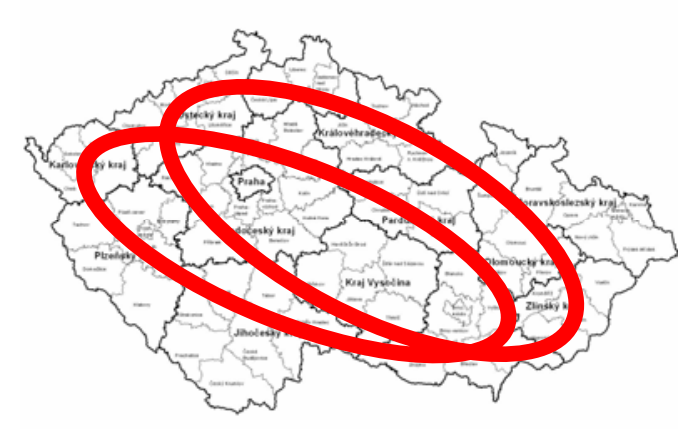

Fig. 5. Normal circuit topology 
The big power plants, especially nuclear power plants or hydraulic power plants supply energy to this network. Big power plants are defined as power plants that produce more than $500 \mathrm{MW}$ of power energy.

This very high voltage level can be used because the conductor is constructed of very durable material. The conductor usually consists of a triple bundle, or sometimes a double bundle on $220 \mathrm{kV}$.

The Transmission and Distribution networks are usually provided by overhead lines. The overhead line grid costs less than a cable line grid. However, many problems exist with overhead grid designs, including mechanical stress, erosion, wind, temperature differences, and the presence of trees. Furthermore, there are many places where overhead grid cannot be used and thus must be replaced with cable grid, such as airports heliports, cities, or residential areas.

\section{Basic information about distribution network}

The Distribution network consists of an Effectively Grounded System on 110kV, a Resonant Neutral System on $35 \mathrm{kV}$, and $22 \mathrm{kV}$, and an Isolated System on $10 \mathrm{kV}$ and $6 \mathrm{kV}$. This network is connected by circuit-branch way. Delivery grid or HVN (high voltage network) is connected between VHVN and LVN or connect large factory to energetic grid.

The Resonant Neutral System is connected to the ground, but there is resistance between the earth and node, thus, there are only three phases conductors. The resistance can compensate short circuit current. The Petersen inductor $\left(\mathrm{P}_{\mathrm{tl}}\right)$ can reduce short circuit current close to zero ampere and is usually used in the same manner as resistance in the Czech Republic. The voltage in broken phase goes to zero voltage, but the voltage on the other phases grows up on line voltage ( $\sqrt{3}$ x phase's voltage).

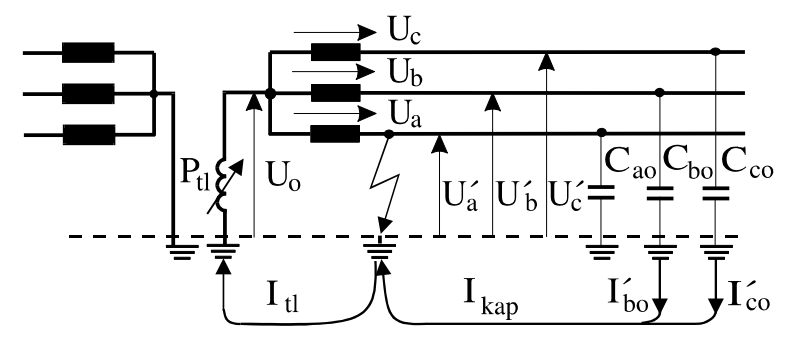

Fig. 6. Resonant Neutral System

For a calculation conductor is necessary to know current which must flow during conductor. This current has the same value as the capacity current, but it has a different vector.

$$
\begin{aligned}
& \left|I_{T L}\right|=\left|I_{K A P}\right| \\
& I_{K A P}=\sqrt{3} \cdot U_{N} \cdot \omega \cdot C_{0} \cdot l \quad[A] \\
& \quad l_{\_}[\mathrm{km}] \quad C_{0} \_ \text {is_capaticance_susceptation }
\end{aligned}
$$

The Isolated System is not connected with the earth and thus contains three phase conductors. This network has a low short current $(20$ A). This current is a capacity current, because resistance between the node and the earth is very high. The voltage in broken phase goes to zero voltage, but the voltage on the other phases grows up on line voltage ( $\sqrt{3}$ x phase's voltage).

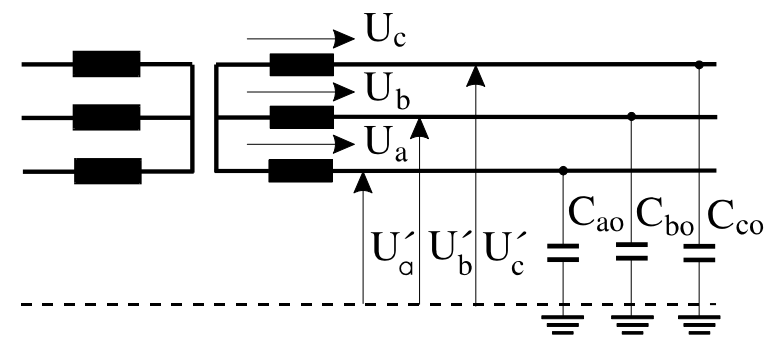

Fig. 7. Isolated Systems

The capacity current in an Isolated System must be lower then $20 \mathrm{~A}$; when the capacity current is higher, the network must be changed to a Resonant Neutral System. So for this reason is necessary know a capacity current:

$$
\begin{aligned}
& I_{K A P}=\sqrt{3} \cdot U_{N} \cdot \omega \cdot C_{0} \cdot l \quad[A] \\
& \quad l_{\_}[\mathrm{km}] \quad C_{0}{ }_{-}{ }^{\prime} \_ \text {capaticance_susceptation }
\end{aligned}
$$

The circuit-branch way is created from a circuit and branch way network as es shown on Fig. 8 and 9. A graph of a distribution network is the geometric formation created by replacing all the network elements by directed nodes connection. A loop is a sequence of the defined number of no crossing branches, which are connected to the nodes in such a sequence, that one can return back to the initial point of the first branch. To the rest place is power energy sanded by branch way. That means by one or two transmission but on one tower.

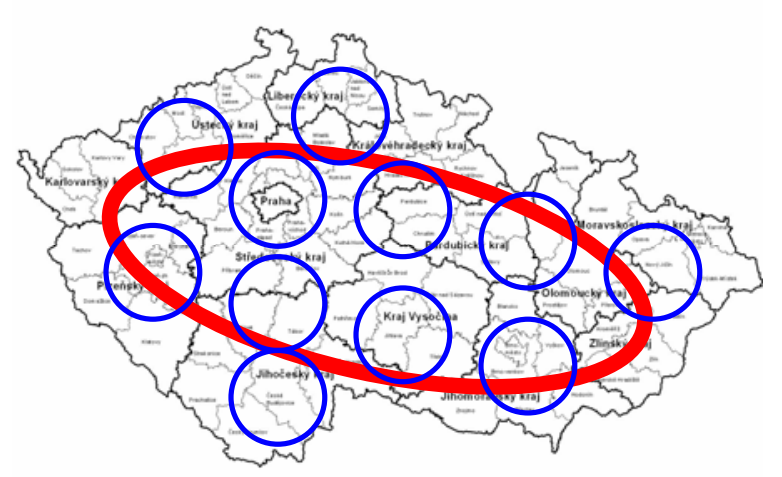

Fig. 8 Circuit-branch topology

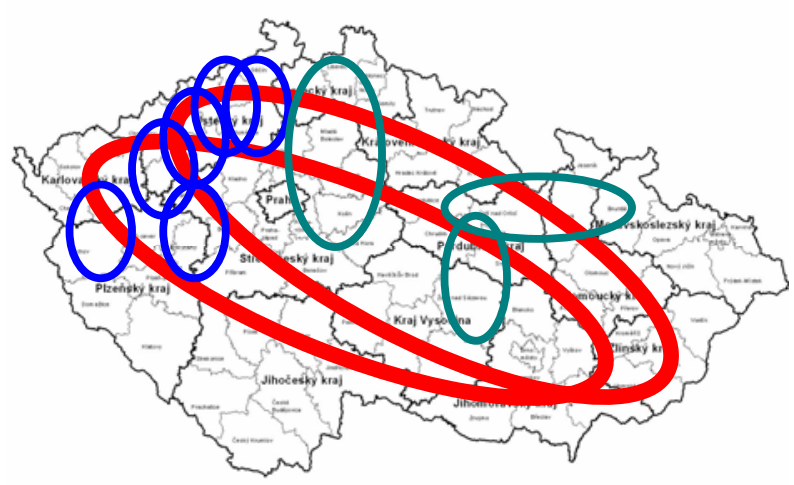

Fig. 9 Real circuit-branch topology 
On this figure (Fig. 9.) is shown only example this topology, because all topology will make this figure not providing an easy survey.

\section{Czech distribution network}

The CEZ distribution, Inc., holds a license for distribution electricity and operator distributive system. The CEZ distribution Inc. is responsible for nine territories, namely: Plzeňského, Karlovarského, Ústeckého, Středočeského, Libereckého, Královehradeckého, Pardubického, Olomouckého and Moravskoslezského, they are show on fig. 10. The main mission is company's distribution seat power control energy physical and juridical men and stable economy escalation qualities and credibility gap supplies to all customers.

The competing company CEZ Distribution Inc. repairs fiduciary assets (technology and related arrangement distributive system) and achievement proprietary law above those assets, including reservation care of consumer from look distribution on all suspense levels of and drive system in real-time.

A list of transmission system facilities is given in the table below.

TABLE III. Technical information CEZ

\begin{tabular}{|c|c|c|}
\hline CEZ Distribution Inc. & Unit & Year 2006 \\
\hline Supply area & $\mathrm{km} 2$ & 52697 \\
\hline Download place & piece & 3475044 \\
\hline From VHVL and HVL & Piece & 13385 \\
\hline Firm on LVL & Piece & 481934 \\
\hline Families on LVL & Piece & 2979725 \\
\hline Maximum download & MW & 6074 \\
\hline Longitude circuit & $\mathrm{km}$ & 152733 \\
\hline On VHVL & $\mathrm{km}$ & 9523 \\
\hline On HVL & $\mathrm{km}$ & 49781 \\
\hline On LVL & $\mathrm{km}$ & 93429 \\
\hline Transformers station & Piece & 49211 \\
\hline Control CEZ Distribution & Piece & 39117 \\
\hline Control by customers & piece & 10094 \\
\hline
\end{tabular}

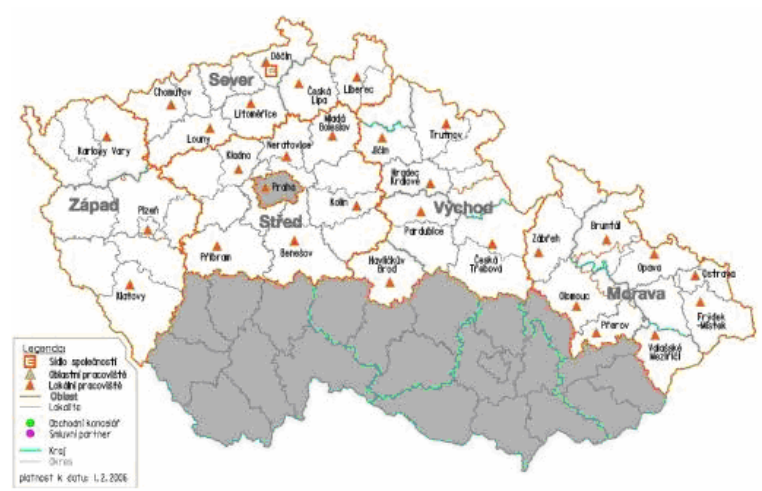

Fig. 10. map of CEZ Distribution regions
The E.ON Distribution Inc., is another company involved in distribution networks. This company is located in the southern part of the Czech Republic.

Within the E.ON energy group in the Czech Republic, E.ON Distribuce, Inc. is responsible for running the distribution network and handling and disputes that arise amongst participants in the energy market. It is licensed pursuant to the Energy Act and regulated by the Energy Regulation Office (ERO). Also imperative for the group as a whole is the realization of economic activities, especially concerning obligations of regulated subjects in respect to ERO and other institutions. Additionally, ECD collaborates very closely with the Ministry of Industry and Trade of the Czech Republic.

Thanks to technological advancement and the continuous effort of specialists employed by the company, EON is now successfully able to provide reliable electricity supplies of an optimum quality. Thus, the vast majority of customers do not have to handle the technical issues connected with reliable electricity supply and have more time to make use of the countless possibilities that electricity offers them. A list of transmission system facilities is shown on tab. 4.

TABLE IV. Technical information E.ON

\begin{tabular}{|l|l|l|}
\hline E.ON Distribution Inc. & Unit & Year 2007 \\
\hline Supply area & $\mathrm{km} 2$ & 26499 \\
\hline Maximum download & $\mathrm{MW}$ & 4575 \\
\hline Longitude circuit & $\mathrm{km}$ & 152733 \\
\hline \multicolumn{1}{|c|}{ On VHVL } & $\mathrm{km}$ & 3876 \\
\hline On HVL & $\mathrm{km}$ & 21745 \\
\hline On LVL & $\mathrm{km}$ & 38837 \\
\hline Transformers station VHVL/ HVL & Piece & 78 \\
\hline Transformers station HVL/ LVL & Piece & 145 \\
\hline
\end{tabular}

The PRE Distribution Inc. is the final company that handles distribution networks. This company is responsible for only the city of Prague (Praha), the capital of the Czech Republic as es shown on fig. 11.

The PRE Distribution manages electricity for the territory within the metropolitan area of Prague. This distributive region contains a highly concentrated population and industry with high demands on reliability and quality of the electric supply so on facture of all part distribution network from distribution point and transformed when after cable tunnel. The technical data are shown on tab. 5 .

TABLE V. Technical information PRE

\begin{tabular}{|l|l|l|}
\hline PRE Distribution Inc. & Unit & Year 2007 \\
\hline Maximum download & MW & 2514 \\
\hline Longitude circuit & $\mathrm{km}$ & 152733 \\
\hline On VHVL & $\mathrm{km}$ & 197 \\
\hline On HVL & $\mathrm{km}$ & 3584 \\
\hline On LVL & $\mathrm{km}$ & 7558 \\
\hline Transformers station VHVL/ HVL & Piece & 20 \\
\hline
\end{tabular}




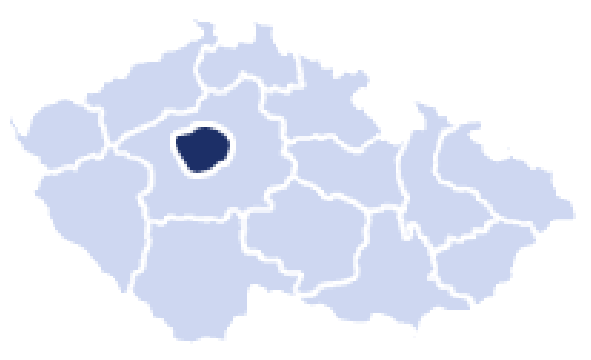

Fig. 11. Map of PRE regions

\section{Spanish distribution network}

ENDESA is the main company in the Spanish electricity system. ENDESA is the foremost electrical company in Spain and the first private utility in Chile, Argentina, Colombia and Peru and has business in Brazil. It is a leading operator on the European side of the Mediterranean, especially in Italy, and is also active in other European countries.

In 2004, ENDESA Spain, with an install capacity of 21 $602 \mathrm{MW}$, sold $29202 \mathrm{GWh}$ in the liberalized customer market, which signifies a market share of $36.6 \%$, and distributed $65645 \mathrm{GWh}$ to about 10.5 million customers, representing a share of $44.5 \%$ in the regulated market.

The distribution market of ENDESA in Spain encompasses close to $200,000 \mathrm{~km}^{2}$, distributed over 20 provinces of the Self-Governing Communities of Catalonia, Andalusia, Extremadura, Canary Islands, Balearic Islands, Aragon, and Castile-Leon, which together have a population of approximately 20 million inhabitants.

In 2004, investments in the company totaled 1122 million euros. These investments have been directed toward improving the quality of service, covering substantial market growth, environmental conservation and providing electricity to rural areas.

ENDESA's electricity transport and distribution lines at the end of the fiscal year 2004 totaled $295,654 \mathrm{Km}$., of which $23 \%$ corresponded to underground lines, which as shown on Tab. 6.

TABLE VI. Technical information ENDESA

\begin{tabular}{|l|l|l|}
\hline ENDESA Distribution Inc. & Unit & Year 2006 \\
\hline Supply area & $\mathrm{km} 2$ & 200000 \\
\hline Download place & piece & 10500000 \\
\hline Maximum download & $\mathrm{GW}$ & 65,65 \\
\hline Longitude circuit & $\mathrm{km}$ & 295654 \\
\hline Transformers station & Piece & 131141 \\
\hline
\end{tabular}

The UNION FENOSA, S.A. was set up by a public document on 10 February 1912, under the name Unión Eléctrica Madrileña, S.A. On 16 October 2001, it changed its name to UNION FENOSA, S.A., and is a registered office of the Company.

The Company was set up for an indefinite duration and its business, according to article 2 of the Articles of Association, is, amongst other things, the operation of production, sale and use of electrical and other power sources, and the carrying out of studies. The principle focus of these studies is the use of all types of primary solid, liquid or gaseous energy resources, including specifically hydrocarbons and gas, whether natural, liquefied, or of any other form.

The UNION FENOSA is a Spanish gas and electricity company present in 12 countries. They provide services to almost 8.5 million customers throughout the world who consume $50 \mathrm{GWh}$ of electricity and more than 38 GWh of gas.

The Group's total installed generation capacity available to meet the needs of its customers is 9,952 MW. $27.4 \%$ of this total generating capacity is operated outside of Spain.

The Spanish technical information are gift to tab. 7 .

Internationally, the Group is a benchmark company in the production and supply of electricity in Latin America. It also has significant interests in the gas business and participates in the development of large gas infrastructure projects in Egypt and Oman.

TABLE VII. Technical information Union Fenosa

\begin{tabular}{|l|l|l|}
\hline Union Fenosa S.A. & Unit & Year 2006 \\
\hline Maximum download & MW & 10321 \\
\hline Hydraulics & MW & 2772 \\
\hline Nuclear & MW & 589 \\
\hline Thermal of Coal & MW & 2048 \\
\hline Combined cycles Gas (2) & MW & 3493 \\
\hline Special regime & MW & 300 \\
\hline
\end{tabular}

The main aims of the IBERDROLA Generation Area, one of Europe's leading electricity companies and the largest Spanish company in terms of installed power, are to develop, operate and maintain all types of electrical energy generation installations (both in terms of those owned as well as those shared), and to be a global operator in wholesale energy markets with a capability for trading as well as continuing to promote technological development and innovation.

Year after year, IBERDROLA's production equipment shows itself to be more diversified and highly competitive, amounting to a total installed power of 30,384 MW. 25,966 MW are located in Spain, where the company is a leader in the construction programme for combined cycle power stations. This technological leadership is exemplified by participation in projects such as the start-up of the Castellón $4(800 \mathrm{MW})$ power station, reaching an operational power of 5,600 MW in Spain (6,400 MW managed). Others technical information are shown on tab. 8 .

Moreover, to meet new needs detected in the system (peak coverage and regulation), Iberdrola will begin a programme for building hydro-electric power stations (both pumping and conventional), which will be more flexible and free from $\mathrm{CO}_{2}$ emissions. The programme will extend beyond 2009 and aims to generate 1,650 MW.

In 2006, IBERDROLA exceeded the targets forecasted in the Grid Plan, included in the Strategic Plan, and focused on increasing and maintaining distribution infrastructures and maximizing service quality. 
TABLE VIII. Technical information IBERDROLA

\begin{tabular}{|l|l|l|}
\hline Iberdrola & Unit & Year 2006 \\
\hline Supply area & $\mathrm{km} 2$ & 190000 \\
\hline Download place & piece & 4500000 \\
\hline Maximum download & $\mathrm{MW}$ & 95102 \\
\hline Longitude on VHVL & $\mathrm{km}$ & 18200 \\
\hline Longitude on HVL and LVL & $\mathrm{km}$ & 200000 \\
\hline Transformers station & Piece & 78468 \\
\hline
\end{tabular}

\section{The UCTE connection}

The Union for the Co-ordination of Transmission of Electricity (UCTE) coordinates the operation and development of the electricity transmission grid from Portugal to Poland and from the Netherlands to Romania and Greece. UCTE, the association of transmission system operators in 23 countries in continental Europe, provides a reliable market platform to all participants of the Internal Electricity Market (IEM) and beyond.

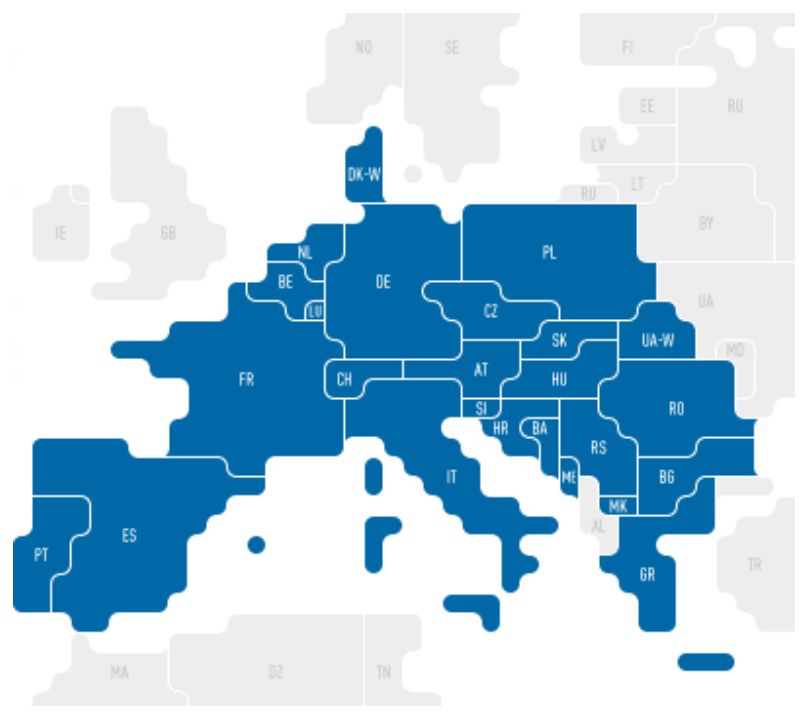

Fig. 12. The map of UCTE regions

The UCTE ensures an efficient and secure operation of the interconnected electrical "power highways" and gives signals to markets when system adequacy declines. For more than fifty years, UCTE has been issuing all technical standards indispensable for co-ordination of the international operation of high voltage grids, which all work at one "heartbeat": the $50 \mathrm{~Hz}$ UCTE frequency. This frequency reflects the nominal balance between offer and demand. The UCTE network provides a safe electricity supply for some 430 million people in one of the biggest synchronous electrical interconnections worldwide.

\section{Comparison of the networks}

The transmission networks in both countries are similar. Both networks consist of the same voltage level, $400 \mathrm{kV}$ to $110 \mathrm{kV}$, the same frequency, $50 \mathrm{~Hz}$, similar network topology, and similar connections with neighboring countries. Additionally, the transmission networks utilize identical power sources, similar transmission line towers, the same materials for overhead lines and cables, and both countries are connected to the UCTE grid..

Red Electrica de Espaňa S.A. operates the high voltage transmission network in Spain. Until 1997, this company owned $95 \%$ of the $400 \mathrm{kV}$ lines and $30 \%$ of the $220 \mathrm{kV}$ lines in Spain. The Red Eletrica is $60 \%$ governmentowned. The remaining $40 \%$ is shared between the four main distributors, who each own $10 \%$ of the company.

In Spain, there are four main issues regarding electricity market reforms that the government may wish to consider to achieve the maximum benefit from its efforts to date. The most important of these is the prospect for slow development of conception, particularly in the generation market. The two largest companies, Endesa and Iberdrola, produce $76 \%$ of the power energy in the Spain. The Czech energy system is momentarily experiencing overuse of its transmission grid, but the grid is expected to achieve sufficient capacity within a few years. The Czech transmission grid has good topology, as the grid consists of two circuit network which are connected at two points.

The Czech energy system has not suffered from major problems with frequency toleration and grid stabilities. Frequency stability is regulated on three levels. These levels are primary regulation frequency, secondary regulation frequency of active power, and tertiary regulation of active power.

Another regulation that allows for better stability is the daily-load curve. This diagram is created prior to each day. The diagram depicts electricity consumption and powers sources connected to the grid. It includes Operating reserve, Control reserve and Central control reserve, and is used to create a bill of quantities for each power source.

Spanish electricity distribution to 21 million consumers occurs through a company operating under a concession granted by the autonomous regional authorities or the national government. There are also 516 small distributors that form cooperatives to purchase power from the surrounding utilities, supplying about 200000 customers.

The Dlouhé Stráně Hydroelectric Power Station is situated in Moravia in the Czech Republic. It prides itself on three superlatives: it has the largest reversing water turbine in Europe, at $325 \mathrm{MW}$; it has the largest head of all power stations in the Czech Republic, at $510.7 \mathrm{~m}$; and it has the largest installed capacity in the Czech Republic, at $2 \times 325 \mathrm{MW}$. The administration building and the control room are situated on the surface, along with the outgoing lines with a $400 \mathrm{kV}$ encased switching station, workshops and warehouses, garages, a sewage treatment station and a water treatment station. 
TABLE IX. Source of Czech and Spain energy

\begin{tabular}{|l|l|l|l|l|l|l|l|}
\hline SPAIN & REE & Endesa & Iberdrola & Union Finosa & Total (GW) & CZECH \\
\hline Instaled & $43,4 \mathrm{GW}$ & $22,9 \mathrm{GW}$ & $24,5 \mathrm{GW}$ & $10,3 \mathrm{GW}$ & $\mathbf{1 0 1 , 0 7}$ & Total v \% \\
\hline Coal & $35 \%$ & $28,10 \%$ & $4,80 \%$ & $19,80 \%$ & $\mathbf{2 4 , 8 4}$ & $\mathbf{6 7 , 2}$ \\
\hline Nuclear & $31 \%$ & $15,50 \%$ & $12,90 \%$ & $5,70 \%$ & $\mathbf{2 0 , 7 5}$ & $\mathbf{1 7 , 8}$ \\
\hline Hydro & $20 \%$ & $24,50 \%$ & $34 \%$ & $26,80 \%$ & $\mathbf{2 5 , 3 8}$ & $\mathbf{1 1 , 0}$ \\
\hline Gas & $7 \%$ & $24,60 \%$ & $0,00 \%$ & $0 \%$ & $\mathbf{8 , 6 7}$ & $\mathbf{0}$ \\
\hline CCGT & $1 \%$ & $7,30 \%$ & $20,10 \%$ & $33,80 \%$ & $\mathbf{1 0 , 5 1}$ & $\mathbf{2}$ \\
\hline Oil & $6 \%$ & $0 \%$ & $11,20 \%$ & $0 \%$ & $\mathbf{5 , 3 5}$ & $\mathbf{0}$ \\
\hline Wint & $0 \%$ & $0 \%$ & $17 \%$ & $14 \%$ & $\mathbf{5 , 5 7}$ & $\mathbf{2}$ \\
\hline
\end{tabular}

\section{Conclusion}

To better illustrate issues concerning stability and correct frequency, the following tables and figures (Table 9; Figures 13,14) summarize power sources in both Spain and the Czech Republic.

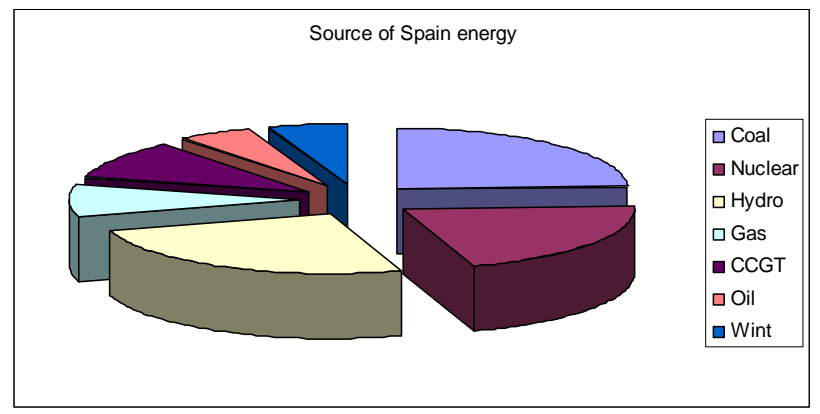

Fig. 13. Sources of Spanish energy

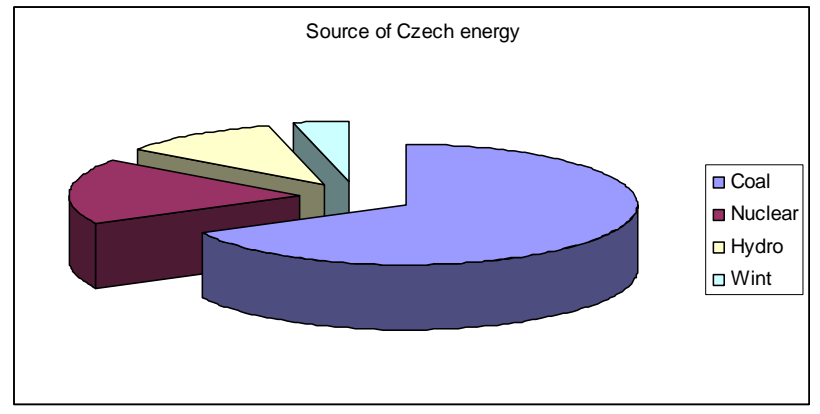

Fig. 14. Sources of Czech energy

As Figure 14 illustrates, coal is the main source of power in the Czech Republic. In Spain fig. 13 are coal, nuclear, and hydroelectric power is the major sources of power and contributes the same percentage of energy. Though the Spanish system is [reason why it's better- more diversified, more sustainable], this energetic system should consider incorporating more hydropower plants with reversing turbines for saving energy for use during peak times in the daily-load curve. Spain contains many hills and water supplies that would allow for the construction of these power stations.
In a few years, both countries can expect problems maintaining stable energetic systems because the use of wind energy has rapidly increased. The energy system is likely to have problems with excess energy during periods of high winds and low energy periods of less wind. To prevent system disintegration at this time, scientists must develop new technology to connect wind and solar energy to the energetic grid. At this time, only three options exist for preventing this situation. The first is reversing turbine for fast regulation. The second option is to use capacitors or batteries to store energy at wind power station fields. Finally, the third option is to create special semiconductor technology for use in controlling network stability.

\section{Reference}

[1]Mertlová,Hejtmánková: Teorie přenosu a rozvodu elektrické energie, Plzeň 2004

[2]Rajský: Preventing faults in a distribution network, Pernink 2006

[3]Rajský: Analýza a matematické modelování ustálených dějů, Plzeň 2007

[4]Rajský: Modeling and analysis capacitance, Elektronika a informatika 2007

[5] www.ceps.cz ; www.cez.cz ; www.eon.cz ; www.pre.cz;

[6] www.ree.es ; www.endesa.es ; www.iberdrola.es ; www.unionfenosa.es ;

[7] Reform in electricity sector: http://www.oecd.org/dataoecd/24/0/2508374.pdf 